\title{
Subject Analysis in Iran's Local Historiography 1722-1925
}

\author{
Moloud Sotoudeh $^{1}$, Morteza Nouraei ${ }^{1} \&$ Aliakbar Kajbaf ${ }^{1}$ \\ ${ }^{1}$ Litrature Faculty, Isfahan University, Isfahan, Iran \\ Correspondence: Moloud Sotoudeh, Litrature Faculty, University of Isfahan, Isfahan, Iran. E-mail: \\ asnadmeli1@yahoo.com
}

Received: November 14, 2012 Accepted: D ecember 27, 2012 Online Published: March 22, 2013

doi:10.5539/ach.v5n2p104

URL: http://dx.doi.org/10.5539/ach.v5n2p104

\begin{abstract}
Subjects can be assumed as phenomena possessing independent axes on which intellectual and material achievements are deployed into a network of interconnections that, centered on certain axes in specific place and time, may give rise to a series of subjects or may transform into turning points that inevitably lead to dimming or elimination of a range of issues and bring about significant changes and developments in another broad range of them. Phenomena such as local governments/states formation or collapse, industrial revolution, and other phenomena such as new civil laws, the press, public education, etc., in any given period can be new issues affecting the situation before and after them, transforming into turning points and/or serving as axes for other subjects. By identifying a network of such subjects, we will be able to understand their process of formation, evolution and variation within the scope of local histories.
\end{abstract}

Keywords: dimensions of local historiography, Iran's local historiography, Iran, subject analysis, network subjects

\section{Introduction}

Social life is cumulated with various subjects that, on a daily basis, some of them decline while some others emerge and strengthen other subjects which are in the middle of their life cycle; or set the ground for their decline. These varying subjects have always been the sources for historiographers with the difference that sometimes the coming and going of dynasties and kings formed the core of histories; and sometimes the histories of the cities and their populations became the main subjects as titled as 'classes', 'genealogies', recorded as a part of local histories in which, the historians indicate specific subjects such as great men's biographies, people's daily life, schools, trades, bazaar, streets, mosques, and so on, which despite of being readily accessible by the historian and look very simple to describe, represent the roots of social developments in the heart of history and during each period. The present paper examines Iran' local histories, with a focus on the period between Safavids' collapse and late Qajari, posing some questions on the nature of (the) subjects, as well as dimensions (subject, time, and place) of Iranian local historiography. To achieve this, and in order to recognize the subjects across Iranian local histories and their process of development, authors have used the actions, reactions and their relationships in certain places (e.g., cities and states) and times (e.g., the study period).

In general histories, the main focuses of historians consist of subjects such as power, kings' enthronement and fall, dynasties' developments, wars and inter-state relationships. But some others have focused on subjects that have had a greater contribution in societies despite of being neglected and having received less attention. Local historians, due to their feelings for their hometowns, have focused more on societal and local issues, trying to show their co-citizens' material and intellectual achievements and their role in civilization, from distant past until their times. These historians have recorded some sets of varied issues on specific cities or regions from their formation to their own times, based on ancient texts or their own observations. Some subjects have been described in detail due to their significance (e.g., reasons why a certain city was born), while other issues are less discussed or not expressed at all, remaining ambiguous (e.g., proprietorship, social relations, various classes, trades, etc.). In order to achieve a brighter view of the past, one could examine the accumulation or dispersion of local issues on which the historians have emphasized most. In this approach, subjects are considered as data which shed light on the 'countenances' of local histories from distant past based on the concepts they convey and the significance assigned to them or attention received from the historians. Assuming any message, account or statement from the past as a datum, the data analysis approach in the Grounded Theory can be readily used. Thus historical data are qualitatively and quantitatively examined in three phases: 1) finding key subject(s) and coding 
them (open coding); 2) moving to axial subject(s) (axial coding); and 3) selection of subject(s)(selective coding) based on the society's focus on its own specific subjects as well as historians' attention and choices in any given period (Nooraee 1390; groundedtheory.htm).

\section{Dimensions of Local Historiography}

Emergence of Islam and its introduction to Iran is one of the most important historical events of this land which led to a shift from ancient to Islamic history of Iran. Following this significant development, historians focused their efforts on recording the history around the axis of Islam and its Holy Prophet (Rosenthal, 1365). But after a short time, Muslim historiography found more variation under the influence of Iranians' history-writing, and many accounts with subjects such as prophets, nations and countries, Prophet's holy wars, conquests, Caliphs, Sultans, Viziers, states and eras, religions and sects, classes and men, incidents and deaths, tombs and shrines were written throughout subsequent centuries (Zarrinkoob,1387).

Early Muslim historians wrote 'informative' accounts where they reported Hadith and Muhaddithin. Later on, the annuals, histories of generations and descendants, classes, encyclopedic histories and genealogies were added as branches of historiography. Historians of early centuries after Islam mostly focused on subjects and chronologies of events but when history of classes was introduced, elements of place were also included due to ethnic pride and fanaticism (Sadjadi, 1383). Along with this development, some sort of encyclopedic historiography appeared that had the cities as its major concern (e.g., Khatibi's "History of Baghdad"; Sahmi's "History of Jorjan"; Nasafi's "History of Samarkand"; etc.). Extended histories are considered as the first steps in formation of subject-based ones, known as local histories the core of which became a sense of patriotism mixed with local pride and an expression of urban life styles (Spuhler, 1380). Afterwards, any local history included three major components: subject, place and time, in a more complete fashion; and formed the main line of local historiography.

These three components that had an independent nature, collectively prepared the ground for recording a network of subjects encompassing a broad range of other subjects. That is, those components could have general or specific concepts. By 'general concept' one indicates the fact that those concepts could be observed at any place and time; and whenever they were limited to a specific area , a subject or a set of subjects would be limited to a single region, city, village or neighborhood and it would be hard to find its/their traces elsewhere. For example, in the study of subjects such as daily life, customs, ways of living, methods of hunting and their comparison in different parts of Iran, a wide range of discrepancies is noticeable to the extent that they are assigned to a location or a place. Some scholars have focused on the cause of this discrepancy in mood and manners of people at national and locational scale and considered them due to their position on the globe, and in a more limited extent, affected by the climate produced by the evaporation from their location of residence (Farabi, 1358).

\subsection{Subject}

It seems that subject in different periods may reflect the necessity of a time when every generation would like to be aware of that. In other words, historians have sought topics that their contemporaries would like to know them through the lens of past times. Subjects in local/regional cycles are not an exception to this. Subjects which are pointed out in local histories are either products of human will or natural forces. Those originating from human will appear both materially and intellectually, and can be transferred and spread; form a primary core for the subject; relate to other subjects in a systematic and goal-oriented framework; and direct the efforts toward their emergence, development and/or actualization.

A subject's core consists of its joining point or its strengthening and linking point. This core might remain independent and create other subjects which in this case it could strengthen and support other material/concrete and intellectual/abstract subjects; or attract consistent subjects to its core; or repel the inconsistent ones. This is how subject boundaries are established, differentiating subject areas and scopes. Necessities, societal demands, efforts to improve life in any place and region, and at any time period, form the space around that core which can be hypothesized as a generating force for other marginal subjects. Given the stability of some subjects and variability of some others, their life cycle may be regarded as consisting of three phases: emergence, prosperity, and decline, formed within a network of interrelated subjects. An independent subject can survive as long as it is capable of maintaining its original sense and bringing about changes in other subjects. Many subjects governing individual and collective spirit can be included in this category; but when facing subjects with stronger cores and capable of attracting other subject components, the one with a weaker core will undergo significant changes leading to its dissolution into another subject and subsequent breakdown. Subjects such as modern knowledge and technology, telegraph, and modern social attitudes, although intended to bring comfort and welfare to the 
whole society, lead to changes in marginal subjects and their survival methodologies that force the current subjects to change, evolve or even decline.

As new subjects are introduced, some current ones gradually turn old-fashioned and begin to fade, leaving no traces behind (e.g., health status, feudalism, education systems). Many of the dominant subjects on the personal and social volition are considered as such subjects, particularly since they brought about the welfare of the society. Subjects such as urban planning, communications and the like are matters that do not belong to a person, people or a specific place. Not only have these subjects retained their main core, but also they affected the related subjects. Some of the subjects in dealing with the other subjects with stronger cores will be subjected to change and absorbed in it; in this case the subject will decline and vanish. For example in the history of Iran, national governments has caused the decline of local government which some of them such as the local government of Sistan had ruled for centuries on a wide range of Iran for generations (Saburi and Nasih ,1386), But with the creation of nation-states and government-adopted policies against them, they went under direct administration of the central government. Or one can point out a subject such as medicine which is sporadically mentioned in local historiography. Before the arrival of the Europeans to Iran, Patients were treated with traditional methods, but in Qajar period with the arrival of European physicians, more attention was paid to new medical methods. Gradually by establishing hospitals in some cities or creating quarantines (Sadid Al Saltane , 1363:169), which were devoted to the treatment of locals and destitute, at ports and borders, Local traditional treatment methods were influenced by the new method and its prosperity declined.

\subsubsection{Subject Categorization}

Perhaps the easiest way to categorize the subjects is to divide them into material/concrete subjects- that can be observed/touched; and intellectual/abstract ones which affect the first category both individually and collectively. Historians believe that sometimes a society wants to know how events have happened in a specific time-and-place setting. Social progress can be regarded as matters of intellect. Some historians, in order to find the causes of these events, have brought such subjects into consideration (Stanford, 1386). To achieve this, one may analyze the causes and backgrounds of events/subjects by confining them within time and place borders. Historians have recorded those changes that have been well-understood and worthy of recording, or their tangible consequences have appeared in a society as concrete subjects. Even some local historians have tried to describe the causes, effects and different aspects of those subjects in their own cities and regions. Subjects as defending one's hometown against invaders, local movements, overcoming the problems in a local community, providing new solutions and/or trying to join other small and large communities in a local level, not only are independent subjects themselves, but also can be considered as starting points for many other subjects. In other words, when studying reasons and causes of emergence, survival and cadence of national and local communities, an effort is made to present abstract subjects in a concrete form. For instance, subjects such as freedom-seeking and resistance against oppression have been narrated in Iran's local histories from a very distant past to the author's date- subjects that while having an abstract nature, have been realized by local characters. This is followed by a series of events resulting in the society's freedom and continued material and intellectual existence that have become observable in local histories. These subjects are so important and influential that local historians had no choice but to narrate them. Such non-material and value-oriented subjects, along with demands and interests of the time, have transformed into constant subjects that could not be easily modified.

\subsubsection{Factors Affecting Subject Formation}

One of the main factors in emergence, development and transformation of local subjects has always been the local population who has discarded some subjects and invented some others based on its own demands and interests. But some of those local subjects become social subjects over time and therefore can be transmitted through subsequent generations in a discrete or continuous fashion. That is, the life cycles of many of those subjects are much longer than an individual's, family's or dynasty's life, with some subjects enduring for centuries or managing to maintain their active existence throughout a city's history. Subjects such as building palaces, water supply, and urban utilities are both material and non-material achievements that may not be confined to the time limits of one or more generations and their age/life span covers the periods before and after a specific era, revived and recorded in local histories based on the community's capabilities, needs and demands. Such subjects are developed by individuals but they have a public nature and therefore, they are beyond individuals' control, being only continued by them (Jaberi, 1378).

Subjects such as important events, revolutions, wars, technology, new intellectual systems, national policy, natural disasters and alike, are each turning points that can influence the emergence, continuation or abandonment of local subjects. Some subjects with a changeable nature such as introduction of Islam, 
constitutional revolution, introduction of telegraph and telephone, gravel roads, the press, print, modern schools, etc., if regarded along the history of any location, will outline variable and evolving forms of social systems for every city/place that are able to disclose some very deep notions on the past social links for present-time observer. These subjects embody common concepts, the effects and consequences of which can be observed in the development of urban and local communities, although their methods of implementation have been different due to existing facilities. This process together with influences from the past, the community's need for powerful and human-based intellectual and material structures, time-related conditions, and individual capabilities, has repeated many times throughout the local history, transiting generations' experiences. Thus, not only did the community's vital axes find a new life, but also they created new subjects themselves and the society has become more complete by developing a network of new subjects.

Geographical and social conditions have also affected the dispersion, density, or lack of some subjects in various cities and regions. For example, subjects that are developed while recording the history of a city in the desert, could be significantly different from that of coastal or mountain cities.

\subsubsection{Network of Subjects}

Subjects of local histories are titles selected by local historians for investigation or writing, which they have generated meaning around them in two fields of surface facts and in-depth facts which ,in order to recognize and understand them and to realize their interrelations, the historian had to split the subjects into smaller ones and then place them within a network system of interrelated subjects to make it possible to understand the roots of social actions and reactions in different historical periods. Throughout their life span, the subjects either are included in a network of subjects or include a set of subjects. In other words, subject networks are general titles or subjects that accommodate numerous other small ones which, given the public attention and concentration of subjects around them, have become capable of transforming into a network of subjects and have accommodated a broad range of other subjects based on their own axial attraction, and have come into connections with other subject networks.

Selection of subjects by historians and/or focus of a society on some subjects lead to the fact that the main historiography axes are focused on specific issues in local histories. Therefore, subject axes are formed based on the data accumulation, subjects recording and significance; and this process has created a network of subjects either consciously or unconsciously. For example, the Iranian society which always faced invasions of alien tribes, showed more interest in building, industry and urban affairs and considered them as signs of its own civilization and social and intellectual maturity; a task that could only be performed by scientists and the learned who considered it harder than fighting, killing and plundering (Zarrinkoob, 1387). This idea has become the main axis for thought and practice in many cities and has established links with a broad set of subject networks such as religion, economy, politics, social affairs and arts; and in many local histories, a considerable part of the reports have been assigned to detailed and sometimes repeated descriptions of important buildings such as mosques, schools, palaces, bazaars, as well as crafts, arts and science.

\subsubsection{Signs of Subjects}

Any subject has its own sign by which one may realize its origin, life span, range and borders. Repetition and continuation of a subject in local histories, or its level of dispersion or density within geographical limits may be considered as signs for axes and subject networks, which specifies the grounds of axes and to what extent affect or are affected by other subjects. Some subjects are time-and -place specific and may not be generalized. Some others, while being place-bound, have survived over time. Some others have reduced density and continuity, gradually declining so that in some period there is not even one single sign of them. These signs help study the life span, extension and continuity of subjects both quantitatively (statistically) and qualitatively. For instance, local historians tell about a city's past . Although this attention might be affected by the historian's individual and social interests, but this shows a public interest in it which makes it important. Counting the components and comparing the repetition frequency one may realize the subject's status. For example, in Isfahan's local histories the issue of army has been emphasized and many stories have been told about it (Jenab, 1371). By counting these stories and comparing their number with other stories one may realize that those concerning military spirit and horses have been told more than others. This might suggest the importance of horses and military and their influence in selection of the name 'Isfahan', the city's original hierarchy and freedom-seeking spirit of its people throughout the history.

\subsection{Place}

In local histories, place may become a matrix for other local subjects as well as becoming a subject itself. In other words, place is a specific area in which subjects take form, are eliminated, change or continue to exist. 
Therefore, place not only is a physical, natural or cultural entity (Stanford, 1386), but also it may develop a broad range of subjects and become distinct from any other place for its own unique features (Kammen, 1996). Place may consist of a broad area or a city, a neighborhood, a village, a religious locality, a shrine, etc. That is, any given point could be a ground for local history investigation. Geographical areas are also changeable. In the onset of Iran's traditional historiography, attention was paid to limited number of areas such as Qom, Neishaboor, or Bokhara. But in $9^{\text {th }}$ century, Seyyed Zahiroddin Mar'ashi extended the history from city to region for the first time, writing "History of Tabarestan, Rooyan and Mazandaran" and "History of Gilan and Deylaman". He did so because local links and common destiny led him to to consider more than one city in a continuum (Nooraee, 1391). Later on, in Qajari period this area extended into province and histories such as 'Fars-Nameh Nasseri' and 'Asarol Ajam' on the history of Fars Province and 'Hadigheye Nasseri' and 'Tohfeye Nassseri' on the history of Kordestan Province were written.

\subsection{Time}

Time is a phenomenon without which the study of subjects might be placed into emptiness. Local historians have recorded actions and reactions relating to their selected subjects within a given period of time and in a specific geography, enabling us to study the emergence and life of a specific subject.

In Iran's local histories, time has been regarded by historians both longitudinally and transversely (Nooraee, Historical Geography and Local History, 1390). In longitudinal approach, many local historians describe a city or region along the history (Nader Mirza, 1360). They have considered the first signs of settlement in cities and regions as epochs and subsequently have described the events and incidents in that area throughout the history. Some of these epochs are so ancient that are mixed with legends (Malek, 1344). Some other events specific to a city or region have received more attention because of public interest or historian's bias which in turn give depth to our perspective to the roots and importance of subjects from past to present. Another approach is the transversal one in which the historians come closer to their own era and record multiple subjects within a specific time period- usually their own lifetime- from their hometowns. Transversal approach deals with describing the historians' concurrent events or independently consider political phenomena - such as "Azerbayjan's 18-Year History" in which the author Kasravi has limited the subject within a specific time period due to its inclusiveness; or "Rouzname Mirza Mohammad, Kalantare Fars" which, while being a personal memoir, contains a lot of information on Fars Province between Safavid's fall aftermath and dawn of Qajaris (Mirza, 1362). However one has to notice that many Iranian local histories contain both longitudinal and transversal approaches and local historians have selected and recorded those subjects which were preferred by themselves, important individuals or the whole community.

\section{Conclusion}

Subjects could be assumed as phenomena with independent axes, capable of absorbing related subjects into a network, creating newer subject(s), and extending the investigation fields. Many local subjects have the three periods of birth, evolution and decline. All of subjects do not necessarily pass every period and some of them, being constructed upon unchangeable social laws, possess very strong axes and attractions and not only have not declined over time, but have continued to exist with the capability of creating new subjects. Subjects are formed and evolve in the matrix of time, place and geography. Changeability is a main feature in a subject's life and when it appears within a subject's core or axis, its constituent subjects may also change and transform into other subjects or lead to emergence of new subjects. Material and intellectual (concrete and abstract) factors, significant events, technology, new systems of thought and national policies are among factors affecting creation, change or outdating of local subjects. Additionally, time, place and the geographical environments are the context in which subjects are formed and have evolved, and due to the stillness of Place over the course of time, it has been given more attention and has influenced the writing of local histories.

\section{Refrences}

Farabi, A. N. (1358). Seyasate Madine. Tehran: Society of Irans Philosophy Print.

Fasaee, M. H. H. (1388). Farsname naseri. Mansor Rastegar Fasaee. Tehran: Amirkabir Print.

Jaberi, A. (1378). In J. Soroshyar (Ed.), Tarikh Esfahan. Esfahan, Mashaal.

Jenab, M. (1371). Al-Esfahan. Esfahan, Golha Print.

Kamen, C. (2003). On Doing Local. Walnut Creek, CA: AltaMira Press and American Association of State and Local History. 
Kammen, C. (1996). The Pursuit of Local History: Readings on Theory. American Association for State and Local History.

Malek, S. H. (1344). Ehya -Al - Muluk. Manouchehr Sotoudeh. Tehran: Ketab co.

Mirza, M. K. F. (1362). In A. Eqbal (Ed.), RouzName Mirza Mohammad Kalantare Fars. Ketabkhane Tohori va Ketabkhane Sanaee.

Nader, M. (1360). Tarikh va Joghrafeiaye Dar-Al-Saltane Tabriz. Mohammad Moshiri, Tehran, Eqbal.

Nooraee, M. (1390). Historical Geography and Local History. Mah Book History and Geography, 163.

Rosenthal, F. (1365). The history of Islam's Historiogeraphy.

Saburi, N., \& Zahir, (1386). In M. Sifatgul (Ed.), Shajaratal - Muluk. Tehran: Miras Maktoub.

Sadid, S., \& Kababi, M. A. (1363). In A. Eghtedari (Ed.), Bandar Abbas va KHalij Fars. Tehran: Donyaie Ketab.

Sadjadi, S. S., \& Hadi, A. Z. (1383). Historiogeraphy in Islam. Tehran: Samt.

Spuhler, et al. (1380). Historiogeraphy in Iran. Tehran: Gostareh Print.

Stanford, M. (1386). A Companion to the study of History. Tehran: Samt Print.

Zarrinkoob, A, (1387). Tarikh dar Tarazoo.Tehran: Amirkabir Print. 